\title{
Motherhood and Mistakes about Defeasible Duties to Benefit ${ }^{1}$
}

\author{
Fiona Woollard
}

University of Southampton

\begin{abstract}
Discussion of the behaviour of pregnant women and mothers, in academic literature, medical advice given to mothers, mainstream media and social media, assumes that a mother who fails to do something to benefit her child is liable for moral criticism unless she can provide sufficient countervailing considerations to justify her decision. I reconstruct the normally implicit reasoning that leads to this assumption and show that it is mistaken. First, I show that the discussion assumes that if any action might benefit her child, the mother has a defeasible duty to perform that action. I suggest that this assumption is implicitly supported by two arguments but that each argument is unsound. The first argument conflates moral reasons and defeasible duties; the second misunderstands the scope of a defeasible duty to benefit. This argument has important practical and theoretical implications: practically, it provides a response to a highly damaging discourse on maternal behaviour; theoretically, it
\end{abstract}

\footnotetext{
${ }^{1}$ This paper was presented at the Society of Applied Philosophy Annual Conference, Edinburgh, June 2015 and Taking Pregnancy Seriously in Metaphysics, Ethics and Epistemology Workshop II, University of Southampton, April 2015. I would like to thank the audience at each event for extremely helpful comments. Special thanks go to Elselijn Kingma and Ben Saunders who gave comments on full drafts of the paper and to Pekka Väyrynen and Sophie-Grace Chappell for advice on structure. Very special thanks go to Jeff McMahan who gave very extensive comments on several drafts and, without whom, this paper would not be what it is today.
} 
provides the framework for a clearer understanding of the scope and nature of defeasible duties to benefit.

A recurring mistake influences discussion of the behaviour of pregnant women and mothers (henceforth simply 'mothers'). The mistake is the assumption that a mother who fails to do something to benefit her child must be able to provide sufficient countervailing considerations to justify her decision. It is assumed that in the absence of such a justification the mother is liable to moral criticism. We see this assumption operating in academic literature, medical advice given to mothers, mainstream media and social media. It has pernicious effects on mothers and gender equality, contributing to a culture of pervasive guilt and continuous self-sacrifice that undermines women's emotional wellbeing and discourages pursuit of career or other nondomestic goals. I reconstruct the normally implicit reasoning that leads to this assumption, show that the reasoning assumes that the mother has a defeasible duty to perform any action that could benefit her child, and show that this involves mistakes about what it is to have a defeasible duty to benefit a person. Reflecting on this has important practical and theoretical implications: practically, it provides an argument for changing a highly damaging discourse on maternal behaviour; theoretically, it provides a clearer understanding of the nature and scope of defeasible duties to benefit.

My argument proceeds as follows: In Section I, I introduce the notion of a defeasible duty, defending an understanding of defeasible duties on which if an agent does not comply with a defeasible duty, she can be required to justify her behaviour and is liable to moral censure if unable to do so. In Section II, I explore 
discussions of maternal behaviour in medical advice given to mothers, social media and mainstream media and academic literature and argue that such discussions often either implicitly or explicitly assume that a mother who fails to take an opportunity to benefit her child is required to justify her behaviour and is liable to moral censure if unable to do so. I suggest that this is evidence that it is implicitly or explicitly assumed that she has a defeasible moral duty to take each opportunity to benefit her child. I then argue that this assumption is implicitly supported by two arguments. In Section III, I explain how the Argument from Moral Reason to Benefit may seem to support the assumption, but show that the argument is unsound by showing that potential benefits to others may give rise to a moral reason to act without a defeasible duty to do so. In Section IV, I do the same for the Argument from a Defeasible Duty to Benefit One's Child, arguing that a maternal duty to benefit that entailed a defeasible duty to perform each potentially beneficial act would be intolerably burdensome. Here I respond to important counterexamples in which intuitively parents are required to make extreme sacrifices for the sake of their children. In Section V, I address the potential objection that the discussions are better understood as appealing to a defeasible duty to avoid doing harm. I argue that we cannot appeal to a standard duty to avoid doing harm to justify current moral practices of censuring pregnant women and mothers. In Section VI, I sum up and make some brief comments on what an adequate understanding of maternal duties to benefit would be like.

\section{DEFEASIBLE DUTIES AND LIABILITY TO MORAL CRITICISM}


An agent who has a defeasible moral duty to perform an action is liable to moral censure if she fails to perform the action without being able to provide sufficient countervailing considerations. I defend this connection between defeasible duty and liability to moral censure by arguing that it allows the concept of a defeasible duty to play an important role in moral practice. The concept of a defeasible duty, as I understand it, is part of the mechanism for holding ourselves and others to moral standards. This is something we have strong reasons to want to be able to do.

When I say that an agent who fails to perform the action required by a defeasible duty without being able to provide sufficient countervailing considerations is liable to moral censure, I mean more than that adverse moral judgements would be correct. If the agent is liable to moral censure and no excusing conditions apply, people of appropriate standing may blame the agent. It will normally be appropriate for the agent to feel guilty. There is a long history of connecting moral duty and moral censure. Mill, for example, observed that "We do not call anything wrong unless we mean to imply that a person ought to be punished in some way for doing it; if not by the law, by the opinion of his fellow creatures, if not by opinion, by the reproaches of his own conscience." 2 Failure to comply with a duty implies that blame is appropriate, absent certain defeating conditions. Unless a defeasible duty is outweighed by sufficient

\footnotetext{
2 John Stuart Mill, Utilitarianism, chap. V, sec. 14. See also, for example, P. F. Strawson, "Freedom and Resentment," Proceedings of the British Academy 48 (1962): 1-25; Alan Gibbard, Wise Choices, Apt Feelings (Oxford: Oxford University Press, 1992); Stephen Darwall, The Second Person Standpoint: Morality, Respect and Accountability (Cambridge, Mass.: Harvard University Press, 2006); John Skorupski, "Moral Obligation, Blame, and Self-Governance," Social Philosophy and Policy 27(2010): 158-180.
} 
countervailing considerations, failure to act in accordance with it is failure to comply with a duty. Thus if a defeasible duty is not outweighed, and there are no excusing conditions, blame is appropriate. In addition, if an agent has a defeasible duty to perform an action and does not do so, those with appropriate standing are, absent defeating conditions, entitled - or in some cases even required - to ask the agent to justify her behaviour by citing appropriate countervailing considerations.

Defeasible duties have these features because of the importance of holding each other to moral standards. ${ }^{3}$ The behaviour of others matters to us, both because of its immediate effects and because of the attitudes it implies. The importance of holding others to moral standards requires us to be able to blame people when they behave badly and to be able to require assurance from others that they haven't behaved badly when there is reason to think that they may have done so. This is why defeasible duties imply not just liability to blame if the behaviour is unjustified but also liability to be called upon to justify one's behaviour.

One need not be directly affected to have standing to blame/ call for justification. We have both altruistic and self-directed reasons to be concerned with wrongdoing that affects others. When the victim of wrongdoing, or potential wrongdoing, is weak and vulnerable, others may have a duty to concern themselves even if they are not directly affected. In addition, if you treat a third party badly, this can have serious repercussions for our relationship even

\footnotetext{
3 See Strawson "Freedom and Resentment"; David Owens Shaping the Normative Landscape (Oxford: Oxford University Press, 2012), Chapters 1 and 3; T.M. Scanlon, What We Owe To Each Other (Cambridge, Mass.: Harvard University Press, 2000): 158-168, for discussion of the importance of holding others to moral standards.
} 
if you treat me well. I need you to recognise that certain ways of treating me are impermissible simply in virtue of my status as a person. Treating another person badly suggests that you do not recognise this and thus gives me reason for concern. ${ }^{4}$

Thus, on my understanding, one important thing that the concept of a defeasible duty does is to provide part of the mechanism for holding others to moral standards. It is able to do this because of the implications for liability to moral censure that come with attributions of defeasible duty. This provides part of my defence of my use of the term 'defeasible duty'. I argue that the reader should accept my use of the term 'defeasible duty' because this use of the term picks out a concept that plays an important role in moral practice This does not presume that a concept's having a role in our actual moral practice counts as a form of justification. ${ }^{5}$ Without the concept of a defeasible duty, it would be much more difficult to hold ourselves and others to moral standards. We have strong reasons to want to be able to hold ourselves and others to moral standards. This means that we require a concept like my concept of a defeasible duty.

Some people will use the term 'defeasible duty' differently, in a way that is not connected to liability to moral censure. This may be simply a semantic issue. Nonetheless, my use of the term is not idiosyncratic. It fits with the long history of connecting duty and censure. More importantly, if I am right about the important role this concept plays in moral practice, even those who think we should use the term 'defeasible duty' differently should accept that we need

\footnotetext{
${ }^{4}$ See Scanlon What We Owe to Each Other, pp. 164-165

${ }^{5}$ I thank Jeff McMahan for pressing me on this.
} 
some term that is used as I use 'defeasible duty'. If they accept that, then they can simply read 'defeasible duty' as a term of art in this paper.

It is not always appropriate for most people to morally censure a person who has failed to fulfil a defeasible duty. A vegetarian might believe that a meat eater is under a defeasible duty not to harm other animals, without thinking that she can challenge her dinner companion as he tucks into a steak. ${ }^{6}$ I'm not $^{\prime}$ completely convinced that vegetarians should not challenge meat-eating companions at the table, but if this is so we might explain it in several ways. First, there may be issues of standing. Because eating meat is currently so common, we tend to see people who eat meat as generally not much worse than most people for doing so. Most of us in some area of our lives do something that is wrong but that makes us not much worse than most people. Given this, vegetarians may feel they lack appropriate standing to repeatedly or frequently challenge those who eat meat. ${ }^{7}$ Second, considerations of conviviality give reasons for moral inquisitions to be laid aside during meals. In this case, as in all cases of holding others to moral standards, restraint must be exercised. Entitlement to call for justification does not imply entitlement to continually badger a person with whom you have a moral disagreement. Nonetheless, away from the dinner table and with the exercise of appropriate restraint and humility with respect to our own shortcoming, eating meat is the type of behaviour for

\footnotetext{
${ }^{6}$ I thank Julian Savulescu for this objection.

${ }^{7}$ Of course, as Jeff McMahan pointed out to me, slave owners in the US South were not much worse than other people in the US South at the time. I suspect that contemporary abolitionists were probably told that even if slave ownership is wrong, you should not challenge slave owners at social events. If we think that eating meat is anywhere near as seriously wrong as slave ownership, then we should not be inclined to accept that vegetarians should not challenge meat eaters as they tuck into a steak.
} 
which we can require justification. The meat eating case is not a counterexample to my claims about liability to moral censure. Absent conditions that make doing so inappropriate, people with appropriate standing are entitled to ask the meat eater to justify his behaviour.

The cases above involve conditions that defeat or restrict the connection between defeasible duties and liability to moral censure. I claim that we still have a defeasible duty in such cases. This raises important issues about when we should say that a person has a defeasible duty, given that defeasible duties are by their nature the types of duties that are sometimes defeated and that there is a defeasible connection between defeasible duties and liability to moral censure. We must draw several distinctions here. (1) We must distinguish between a reason to suspend the liability to moral censure for failing to $\varphi$ in a particular case and a standing reason that a person should not be liable to moral censure for failing to $\varphi$. (2) We must distinguish between there being restrictions on the set of persons with appropriate standing to demand justification and it being inappropriate for anyone to demand justification. When there is reason to suspend the liability to censure in a particular case or the set of persons with appropriate standing to demand justification is restricted, we should say that there is a defeasible duty to $\varphi$ but that either the duty itself or the connection to liability to justification is defeated or restricted. In contrast, where there is some standing reason that a person should not be liable to moral censure to anyone for failing to $\varphi$, we should say that there is no defeasible duty to $\varphi .^{8}$

This division of terminology is the best way to respond appropriately to standing reasons to protect people from liability to moral censure - in particular

\footnotetext{
${ }^{8}$ I thank Lindsey Porter for pressing me on this.
} 
from liability to be called on to justify their choices. First, if I were required to call upon standing reasons not to be required to justify my behaviour to explain why I am not liable to moral censure, I would still be required to justify my behaviour. Saying that there is no defeasible duty seems like a more effective way to respond to a standing reason to protect me from liability to be called upon for justification. However, suppose that we could avoid this practical problem with some kind of standing presumption against being called upon to justify oneself with respect to a given duty. In this paper, I will argue that there are standing reasons, related to the costliness of being liable to moral censure, that a mother cannot have a defeasible duty to perform any action that might benefit her child. Suppose someone wanted to say that a mother has a defeasible duty to benefit her child but that either the duty or the liability to justify herself is almost always defeated. Thus there should be a standing presumption that mothers in general are neither open to moral censure nor required to justify themselves when they fail to perform some action that might benefit their child. Mothers would be held to be liable to moral censure or demands for justification only in certain very restricted circumstances. ${ }^{9}$ First, it seems strange to me to insist that there is defeasible duty to perform an action even though there is a presumption that we don't need to be able to point to any justification to avoid moral censure, remembering that moral censure includes guilt as well as blame. How can it make sense to say that there is a defeasible duty if, in almost all circumstances, those who do not comply with the duty are not expected to justify that failure, or to be blamed by others or even to feel bad about their own behaviour? Moreover, it will be no easy matter to explicate the restricted

\footnotetext{
${ }^{9}$ I thank Jeff McMahan for this suggestion.
} 
circumstances under which mothers are to be held liable for moral censure. In such explication we find the really interesting and substantial moral question about maternal duties to benefit. The really interesting question is when do we have that default connection with moral censure: when does failure to benefit a child make a mother liable for blame and guilt unless she can point either to countervailing considerations or to some reason to suspend liability to justify in that particular case? My use of the term 'defeasible duty' identifies this key question with the question "What defeasible duties do mothers have to benefit their children?"10 I take it that it is useful to have a concept that does this and in general to have a concept that picks out when there is a default implication of liability for calls for justification and moral censure. Thus, I echo my earlier response to those who do not wish to use the term 'defeasible duty' in such a way that defeasible duties are connected with moral censure. Such people may, if they wish, read 'defeasible duty' in this paper as a term of art for this useful concept.

\section{ASSUMPTIONS IN THE DISCUSSION OF MATERNAL BEHAVIOUR}

I now argue that discussion of maternal behaviour implicitly or explicitly assumes that if any action could benefit her child, the mother has a defeasible

\footnotetext{
10 One might wonder whether there is a general truth about what defeasible duties mothers have. Perhaps wealthy mothers with only one child and with a great deal of spare time have different defeasible duties from poor working mothers with many other children, etc. I will later suggest that mothers have a duty to love and care for their child, to consider the child's wellbeing and a defeasible duty to give their child a good life and protect them from unreasonable overall risk of harm. I think this duty could apply to all mothers, although of course for some mothers there will be countervailing considerations that either justify or excuse failure to comply with the duty. I thank Jeff McMahan for pressing me on this.
} 
duty to perform that action. First, I show that discussion of maternal behaviour in the media and social media and in advice given to pregnant women and new mothers often treats the mother as required to provide over-riding countervailing considerations to justify a failure to benefit. ${ }^{11}$ Given the links between defeasible duties and liability to provide justification, it makes sense to understand this as an implicit ascription of a defeasible duty to perform each action that could benefit the child. I then show that discussion of maternal behaviour in academic literature often either implicitly or explicitly assumes that there is a defeasible duty to perform each action that could benefit the child.

Before I begin, I should note that I have only argued that if a person has a defeasible duty they are, absent defeating conditions or excuses, liable to moral censure if they do not act in accordance with the duty. It does not follow deductively that discussion that treats pregnant women as liable to moral censure for failure to take an opportunity to benefit her child assumes a defeasible duty to take each opportunity to benefit her child. The argument is abductive: given that ascription of duties implies liability to moral censure, the implicit assumption of moral duty is the best explanation for the assumption of liability to moral censure.

In this section, I argue that the discussion implicitly assumes that mothers have a defeasible duty to take each opportunity to benefit their children. Some readers may suspect that it instead appeals to a duty not to harm or to prevent risk of harm. In Section V, I argue that a duty not to harm or prevent risk of harm cannot justify the moral censure in discussion of maternal behaviour.

\footnotetext{
${ }^{11}$ See Rebecca Kukla, Mass Hysteria, (Lanham, Maryland: Rowman and Littlefield, 2005) pp. 129-130 for discussion of the regulation of pregnant women's lives.
} 
The scrutiny of maternal behaviour begins with ubiquitous pressure for pregnant women to regulate their lifestyles, avoiding risky behaviour and embracing healthier alternatives. Most of us are familiar with the long list of forbidden food: unpasteurised cheese, raw eggs, pâté, raw meat, liver etc. ${ }^{12}$ We see an even more strenuous set of demands for regulation in advice regarding managing chemical risks to foetuses from cosmetics and food packaging, recently published by the Royal College of Obstetricians and Gynaecologists. ${ }^{13}$ The paper recommends a "'safety first' approach, which is to assume there is risk present even when it may be minimal or eventually unfounded."14 Without any evidence of potential harm, women are advised to avoid new cars, new furniture, air fresheners, deodorant, sunscreen ${ }^{15}$, non-stick frying pans, and food in plastic containers. The advice has been widely criticized ${ }^{16}$ but is still displayed on advice boards to pregnant women. ${ }^{17}$

12 "Why should I avoid some foods during pregnancy?" NHS Choices, http://www.nhs.uk/chq/Pages/917.aspx?CategoryID=54 Accessed 3 ${ }^{\text {rd }}$ September 2014. ${ }_{13}$ "Chemical Exposures During Pregnancy: Dealing with Potential, but Unproven, Risks to Child Health", Royal College of Obstetricians and Gynaecologists, Scientific Impact Paper Number 37, (May 2013) Available online at < http://www.rcog.org.uk/files/rcogcorp/5.6.13ChemicalExposures.pdf> 14 "Chemical Exposures During Pregnancy (Scientific Impact Paper 37)" (http://www.rcog.org.uk/womens-health/clinical-guidance/chemical-exposures-duringpregnancy-scientific-impact-paper-37, accessed 25/7/2014)

${ }^{15}$ Given concerns about skin cancer, it seems very odd to describe avoiding sunscreen when there no evidence of risk as a 'safety first' approach. This links into some of Rebecca Kukla's criticisms of the way we evaluate risk in pregnancy in "Equipoise, Uncertainty, and Inductive Risk in Research Involving Pregnant Women", Unpublished.

16 (http:/ / www.bbc.co.uk/news/health-22754944, accessed 25/07/2014)

${ }^{17}$ See for example Pregancy dos and don't, http://www.mumsnet.com/pregnancy/dos-anddonts (accessed 25/07/2014). 
Pregnant woman are advised to moderate their diet not simply to avoid potential risks but also to actively benefit the foetus. ${ }^{18}$ Rebecca Kukla discusses a striking passage from a well-known 'pregnancy bible':

What to Expect When You're Expecting warns, "Every bite counts. Before you close your mouth on a forkful of food, consider 'Is this the best bite I can give my baby?' If it will benefit your baby, chew away. If it'll only benefit your sweet tooth or appease your appetite put your fork down."19 This passage - which regularly incurs the wrath of pregnant woman in chat rooms and on bulletin boards-demands that mothers discipline their eating with literally every bite of food, avoiding the corrupting, selfish bite that is not baby-directed. Here, eating simply because one is hungry ("to appease your appetite") is akin to maternal betrayal.20

The pressure regarding infant feeding after birth is, if anything, even more intense. ${ }^{21}$ In the UK, at every visit to her midwife or antenatal clinic, a pregnant woman is bombarded with posters and leaflets reminding her that she

\footnotetext{
18 The distinction between duties to avoid harm and duties to benefit will be discussed in section $\mathrm{V}$.

${ }^{19}$ Murkoff, Eisenberg, and Hathaway, "What to Expect When You're Expecting", (New York: Workman Publishing, 1985) p. 80. The advice is reprinted in recently revised editions of the text.

${ }^{20}$ Rebecca Kukla, "Measuring Motherhood", International Journal of Feminist Approaches to Bioethics 1 (2008), p. 81

${ }^{21}$ There is some overlap between this paper and Fiona Woollard and Lindsey Porter,

"Breastfeeding and Defeasible Duties to Benefit", work in progress. The latter paper includes a much simplified presentation of the philosophical argument, but more detailed discussion of the sociological evidence and the practical steps that should be taken in response.
} 
must breastfeed to get her baby "off to the best start."22 Her midwife will ask her whether she intends to breastfeed. Should she reply that she does not intend to do so, she will be pressed to explain why not. Many women report midwives asking them to repeatedly defend their decision not to breastfeed.

Breastfeeding is a recurring topic on parenting social media sites such as Mumsnet and Netmums. So high do feelings run on these topics, that breastfeeding threads are almost always removed by moderators after a few days. There is a common pattern: someone will post a comment or link that asks why some/ most women do not breastfeed. Either in the original post or shortly afterwards, it will be suggested that many women who fail to breastfeed are selfish. ${ }^{23}$ Formula feeders typically defend themselves by listing serious reasons that they were unable to breastfeed and emphasising that their children are, nonetheless, thriving. ${ }^{24}$ Although some commentators will argue that a woman's reasons not to breastfeed are no one else's business, the generally unquestioned assumption is that a decision not to breastfeed requires defence and that unless a mother can bring forward weighty extenuating circumstances, she is open to serious criticism if she does not breastfeed. ${ }^{25}$

\footnotetext{
22 "Off To The Best Start Leaflet", Start4Life, <http://www.nhs.uk/start4life/Pages/healthcare-professionals.aspx> ${ }^{23}$ (posted 20-07-14, 11:21 http:// www.netmums.com/coffeehouse/general-coffeehouse-chat514/wine-bar-494/1144816-why-do-hardly-any-women-breast-feed-anymore-2.html) ${ }^{24}$ Comment \#4 (posted 20-07-14, 10:24 http:/ / www.netmums.com/coffeehouse/generalcoffeehouse-chat-514/wine-bar-494/1144816-why-do-hardly-any-women-breast-feedanymore.html)

${ }^{25}$ For a collection of comments from around the web judging maternal behaviour, including many on breastfeeding, see the "Sanctimommy" site (https://www.facebook.com/pages/Sanctimommy/523533471000365 ). I thank Rebecca
} 
Anecdotal evidence of the pressure that many new mothers feel to breastfeed is easy to acquire simply by talking to pregnant women or new mothers. Several sociological studies report an association between decisions to formula feed and feelings of guilt, blame and failure. ${ }^{26}$ Indeed, there is evidence that whatever decision women make about feeding choices they face what Elizabeth Murphy calls a "moral minefield", noting that infant feeding is treated as an "accountable matter" 27 , in other words, mothers feel required to justify their infant feeding decisions and as subject to blame and guilt if they cannot do so. Thomson et al sum this up: "In the wider literature, guilt and blame is frequently cited in association with women's experiences of formula feeding, with discomfort, humiliation and fear appearing as descriptors of experiences of public breastfeeding." 28 Thomson et al's own experimental data supports this conclusion. ${ }^{29}$

Brione for the link. For a fascinating extended discussion of the longstanding public fascination with breastfeeding see Kukla Mass Hysteria, Chapter 2.

${ }^{26}$ See for example, (Lee E. (2007) Health, morality, and infant feeding: British mothers' experiences of formula milk use in the early weeks. Sociology of Health and Illness 29, 10751090; Lakshman R., Ogilvie D. \& Ong K.K. (2009) Mothers' experiences of bottle-feeding: a systematic review of qualitative and quantitative studies. Archives of Disease in Childhood 94, 596-601).

${ }^{27}$ Murphy E. (1999) 'Breast is best': infant feeding decisions and maternal deviance. Sociology of Health and Illness 21, p. 187, p. 205

28 Thomson G, Eschbrich-Burton K, Flacking R. “Shame if you do, Shame if you don't: Women's experiences of infant feeding." Maternal and Child Nutrition 11(1), (2015), p. 35. ${ }^{29}$ Thomson et al's conclude "The findings of this paper highlight how breastfeeding and nonbreastfeeding women may experience judgement and condemnation in interactions with health professionals as well as within community contexts, leading to feelings of failure, inadequacy and isolation." ("Shame if you do, Shame if you don't: Women's experiences of infant feeding", p. 33) 
These examples show that popular discussion of pregnant women and new mothers often assumes that if a women misses an opportunity to benefit her child she is liable to moral censure unless she can provide sufficiently weighty countervailing considerations. I suggest this is because it is assumed that she has a defeasible duty to perform any action that could benefit her child. I say that the discussion assumes that a woman has a defeasible duty to perform each action that could benefit her child rather than that the mother has a defeasible duty to perform each action that will benefit her child. Under the former assumption, whenever there is a chance that an action could benefit their child, mothers are required to justify failure to perform the action. How strong the countervailing considerations need to be to justify failure to benefit will depend on the expected value of the action. This is determined by both the value of benefit in question and the probability that the action will produce that benefit. Given that the benefits are uncertain in many of the cases described above in which the mother is required to justify her behaviour, this seems to me to be the best way to understand the assumption. In Section III, I will argue that retreating to a defeasible duty to perform any action that will benefit the child will neither justify current practices nor provide an adequate account of maternal duties.

Academic literature in bioethics, law and philosophy also often assumes that any opportunity to benefit to the child gives rise to a defeasible duty for the mother. Indeed, a significant proportion of literature discussing maternal behaviour suggests that pregnant women have not merely defeasible but absolute duties to ensure the foetus' wellbeing. The duty of care approach is influential in bioethics, law and philosophy. According to this approach, 
although a woman has a right to choose to abort during early pregnancy, in refraining from doing so she signals her intention to bring the child to term and her acceptance of a duty to ensure a healthy birth..$^{30}$ On this view, pregnant woman who do not abort have not merely an absolute moral duty, but should also have a legal duty, to ensure a healthy birth.

Moderates such as Rosamund Scott respond to these extreme demands by emphasising the defeasibility of maternal duties to benefit. Scott argues that we cannot understand the continuation of a pregnancy as an agreement to undertake all and any sacrifices for the sake of the foetus. ${ }^{31}$ Scott says that the mother has a duty to "do all she can" to benefit the foetus, but emphasises that "doing all she can will be doing all those things which she does not have serious reason to refuse to do". 32

Despite her obvious concern to limit the sacrifices mothers are required to make for the wellbeing of their children, Scott appears to overlook the difference between moral reasons that give rise to defeasible duties and those that do not. For example, Scott discusses “...the purely hypothetical example of a woman refusing to swallow a pill that would greatly enhance fetal welfare and that of the future child..."33 She states that if a mother refuses to take this highly beneficial pill "for no reason" she has "a duty to take the pill for the benefit of the

\footnotetext{
${ }^{30}$ Margery Shaw, "Conditional Prospective Rights of the Fetus", Journal of Legal Medicine 5 (1984); John Robertson, “The Right to Procreate and In Utero Fetal Therapy", Journal of Legal Medicine 3 (1982).

${ }^{31}$ Rosamund Scott, Rights, Duties and the Body: Law and Ethics of Maternal-Fetal Conflict (Portland, Oregon: Hart Publishing, 2002), p.98.

${ }^{32}$ Scott, Rights, Duties and the Body p. 104

${ }^{33}$ Scott, Rights, Duties and the Body, p. 47.
} 
future child." 34 . This is because "swallowing the pill does not appear seriously to invoke her interests either in self-determination or bodily integrity."35 Scott appears to endorse the view that potential benefits to the child give rise to a defeasible duty for the mother: she is required to act to secure these benefits unless she has some strong countervailing reason.

I have given some examples of ways that discussion of maternal behaviour in the media and social media, in advice given to pregnant women and new mothers and in the academic literature treats the mother as required to provide over-riding countervailing considerations to justify a failure to benefit and as liable to moral censure if she cannot do so. I suggest that, given the links between defeasible duties and liability to provide justification, it makes sense to understand this as an implicit or explicit assumption of a defeasible duty to perform each action that could benefit the child. I now attempt to reconstruct the normally implicit reasoning behind this assumption. I suggest it rests on appeal to two arguments, both of which are initially plausible but ultimately unsound.

\section{THE ARGUMENT FROM MORAL REASON TO BENEFIT ONE'S CHILD}

The first argument starts from the uncontroversial claim that a potential benefit to her child gives a mother a moral reason to act. It then implicitly assumes that if a person has a moral reason to perform some action she has a defeasible duty to perform that action and thus concludes that the mother has a defeasible duty to perform each action that could benefit her child.

\footnotetext{
34 Scott, Rights, Duties and the Body, p. 105.

35 Scott, Rights, Duties and the Body, p. 105.
} 
Premise 1: If an action could benefit her child, the mother has a moral reason to perform that action.

Premise 2: Whenever one has a moral reason to perform some action one has a defeasible duty to perform that action.

Conclusion: Therefore a mother has a defeasible duty to perform each action that could benefit her child.

I show that Premise 2 in this argument is false. I begin by arguing that elsewhere we recognise moral reasons which do not give rise to defeasible duties and that we are right to do so. I then show that distinguishing between moral reasons and defeasible duties mirrors the way we think about rationality in general.

We see moral reasons without associated defeasible duties in certain instances of supererogation. Behaviour is supererogatory if it is morally admirable but not morally required. Philosophers tend to focus on dramatic supererogation. In dramatic supererogation I can do something amazing at great cost to myself. Perhaps I can save five people's lives by throwing myself in front of a runaway tram. Dramatic supererogation is not my focus here. Someone who holds that moral reasons always give rise to defeasible duties can account for dramatic supererogation. The high cost to the agent provides a discountable, agent-relative reason that the agent can call upon to justify a failure to aid. ${ }^{36}$ However, much supererogation is not dramatic. Every day we experience countless minor cases of supererogation, in which we are not required to act on a

\footnotetext{
36For this kind of account of supererogation, see Jonathan Dancy, Moral Reasons (Oxford: Blackwell, 1993), Chapters 8 \& 12.
} 
moral reason and need not be able to appeal to any weighty countervailing consideration to explain this. ${ }^{37}$

Suppose running in a sponsored charity race would raise a significant amount of money that could then be used effectively to save lives. I take it that I have a moral reason to run. Nonetheless, I am not liable to moral criticism for failing to run, even if I cannot supply weighty countervailing reasons to justify my failure to do so. We see the same phenomenon when it comes to opportunities to bestow minor benefits in ways that won't compromise your own overall welfare such as reading lines with your sister for her part in the school play (suppose that the time taken up will be roughly compensated for by the educative value of learning some Shakespeare). In each case, you have a moral reason to perform the act in question but you don't need to be able to provide countervailing considerations to avoid censure if you fail to do so. Those who assume that each moral reason gives rise to a defeasible duty are unable to explain these cases.

The cases I have just described are importantly disanalogous to the maternal case. A mother's relationship to her child is very different from her

\footnotetext{
${ }^{37}$ Ben Saunders raises a similar objection against Julian Savulescu's Principle of Procreative Beneficence, according to which, where selection is possible, parents have a defeasible moral obligation to select the child who, on the basis of available evidence, is expected to have the best life (Ben Saunders, "Is Procreative Beneficence Obligatory?", Journal of Medical Ethics 41 (2015): 175-178; Julian Savulescu "Procreative Beneficence: why we should select the best children." Bioethics 15 (2001): 413-26). Saunders uses Mother Teresea's efforts to aid the poor of Calcutta as an example of supererogation. (Saunders, "Is Procreative Beneficence Obligatory?", p. 177) I see Mother Teresa's behaviour as an example of dramatic supererogation that can be explained by those who assume that moral reasons always give rise to defeasible duties. The cases of everyday supererogation described below fit much better with Saunders' key insight: "refusing to act in a supererogatory fashion does not require special justification” (Saunders, “Is Procreative Beneficence Obligatory?” p. 177).
} 
relationship to a stranger. However, my interest in this section is in the argument that moves from the thought that the mother has a moral reason to perform actions that could benefit her child straight to the thought that she has defeasible duty to do so. This argument depends on the premise that a moral reason always gives rise to a defeasible duty. If I can show that this premise is false, I will have undermined this argument. I will address alternative arguments that appeal to the strength of a mother's duty to benefit her child in a later section.

Two considerations explain why the moral reasons in the cases above should not give rise to defeasible duties. The first is an issue of aggregative cost. Although a defeasible duty to perform the act would not be costly in each individual case, a defeasible duty to perform such actions in all such cases would soon lead to a high aggregative cost. ${ }^{38}$ The second consideration is the importance for individual wellbeing of freedom from moral demands, from liability to censure and from being called upon to justify one's decisions. Suppose that every time you have the opportunity to benefit someone, you have a defeasible duty to do so. Remember, if you have a defeasible duty to do something and you don't do it then you are liable to moral censure if you cannot provide sufficient countervailing considerations to justify this failure. Thus you are constantly required to take moral considerations into account, balancing the moral reasons against other demands. Morality, and the moral justifiability of your actions, invades every area of your life. Moreover, if I am right that moral

\footnotetext{
38 This issue arises in discussion of duties to respond to famine relief. See, for example, Garrett Cullity, The Moral Demands of Affluence. (Oxford: Clarendon Press, 2004), p. 85. I thank Ben Saunders for urging me to point out this similarity.
} 
duties allow people with appropriate standing to require justification and to censure you if you are unable to provide such justification, you are constantly open to calls to justify your decisions. Every area of your life becomes the business of others. All this seems to me to be bad for your wellbeing both instrumentally and in its own right. Instrumentally, it is likely to take up significant time and energy and to foster unnecessary worry. In addition, it seems bad in itself for someone have so much of their life subject to moral scrutiny.

Distinguishing between moral reasons and defeasible duties mirrors the way we think about rationality in general. Suppose that I do not do what I have most reason to do. Perhaps I have more reason to go for a swim than to do an exercise video, but I nonetheless do the exercise video. Am I necessarily subject to rational criticism? Many people would say no. Now, there is of course at least one type of rational criticism that is appropriate here: it is true that I have failed to do what I have most reason to do. ${ }^{39}$ Thus the temptation to say that rational criticism is inappropriate must be picking up on some stronger type of rational criticism, which we might call "full-blooded rational criticism". When one is subject to this type of rational criticism, one has behaved irrationally, failing to live up to minimal standards of rationality. It does not seem that I - or my behaviour - can be criticised as "irrational" if I chose to do an exercise video instead of swimming. This seems to be rationally permissible even if not rationally ideal. Joseph Raz calls the claim that we are often rationally permitted to choose between a range of options, "The Basic Belief". ${ }^{40}$ In recognising that

\footnotetext{
${ }^{39}$ I thank Jeff McMahan who pointed this out.

${ }^{40}$ Joseph Raz, "Explaining normativity: reason and the will” in Engaging reason: on the theory
} 
moral reasons need not give rise to defeasible duties, we make similar space for a person to fail to do what they have most moral reason to do without being subject to full-blooded moral criticism. ${ }^{41}$

Explanations of the Basic Belief can be adapted in order to explain how we could have moral reasons to perform an action without a defeasible duty to do so. ${ }^{42}$ For example, Jonathan Dancy distinguishes between enticing and peremptory reasons: “[Some] reasons ... are more to do with making an option attractive rather than demanded, required or right." 43 While peremptory reasons have a deontic focus, and concern what we ought to do, enticing reasons have an evaluative focus, and concern what it would be best to do. ${ }^{44}$ We can produce a Dancy-style explanation of the moral case by arguing that some moral reasons are (morally) ${ }^{45}$ enticing rather than (morally) peremptory. ${ }^{46}$ Which reasons

of value and action. (Oxford, Oxford University Press, 1999), p. 100.

${ }^{41} \mathrm{~A}$ similar point is made by Véronique Munoz-Dardé "The Distribution of Numbers and the Comprehensiveness of Reasons." Proceedings of the Aristotelian Society 105 (2005), p. 203. As Jeff McMahan pointed out to me, the idea that it is not necessarily true that one ought to do what it would be best to do seems to be another way of stating the clearest form of supererogation.

42 For explanations of the Basic Belief, see Dancy, "Enticing Reasons", John Broome, 'Normative Requirements' in Jonathan Dancy (ed.) Normativity (Oxford: Blackwell, 2000), 7899, Patricia Greenspan, “Asymmetrical Practical Reason” in M. E. Reicher, J. C. Marek (Eds.), Experience and Analysis. (2004): 387-394; Joshua Gert, “Normative Strength and the Balance of Reasons" Philosophical Review, 116 (2007): 533-562.

${ }^{43}$ Dancy, "Enticing Reasons", p. 91

${ }^{44}$ Dancy, "Enticing Reasons", p. 117

${ }^{45}$ I leave open the possibility that a reason could be rationally peremptory but morally enticing or vice versa.

${ }^{46}$ This appears to conflict with some of Dancy's own comments, for he suggests that moral reasons can't be merely enticing ("Enticing Reasons", p. 99). Dancy's stance may in part result from his understanding of the moral/non-moral distinction. Elsewhere, he argues that it is not possible to distinguish between moral and non-moral reasons on the basis of content or 
count as morally peremptory will depend upon when an agent who has no excuse for her behaviour should be liable to moral censure/ required to provide justification. This does leave it open for someone to argue that all moral reasons are morally peremptory, but this would be a substantive position requiring substantive argument. The considerations raised above about aggregative cost and the value of freedom from moral demands, mean that there is a good case for holding that some, even some significant, moral reasons are not morally peremptory.

Recognising that not all moral reasons give rise to defeasible duties (a) allows us account for intuitions about supererogation; (b) recognises the importance for wellbeing of freedom from moral demands and (c) fits with appealing intuitions about rationality in general. We should thus reject the Argument From Moral Reason to Benefit One's Child. It is a mistake to move from the uncontroversial premise that a mother has a moral reason to perform an act if it might benefit her child to the conclusion that she has a defeasible duty to perform each action that might benefit her child.

\section{THE ARGUMENT FROM A DEFEASIBLE DUTY TO BENEFIT ONE'S CHILD}

The second argument that a mother has a defeasible duty to perform each action that could benefit her child starts from the belief that that a mother has a

subject matter (Dancy, Moral Reasons, p. 43-44). and therefore seeks to characterize what it is for a reason to be moral in terms of "imperatives" (Dancy, Moral Reasons, p. 47). Insofar as the reasons that I am interested in are indisputably moral, they are so because of their subject matter. In other comments, Dancy seems to assume that enticing reasons must be somewhat trivial. (p. 99) This assumption does not seem to be warranted by Dancy's account of enticing reasons. A reason may be relevant to the evaluative rather than the deontic without being trivial or non-moral. 
defeasible duty to benefit her child. When discussing a mother's decision whether to take an action that could benefit her child, people often move without noticing from this uncontroversial belief to the assumption that the mother has a defeasible duty to perform the particular action in question because it could benefit her child. The underlying assumption is that if one has defeasible duty to benefit a person and a given action could benefit that person, one has a defeasible duty to perform that action. This gives us:

Premise 1': A mother has a defeasible duty to benefit her child.

Premise 2': If one has defeasible duty to benefit a person, and a given action could benefit that person, one has a defeasible duty to perform that action.

Conclusion: Therefore a mother has a defeasible duty to perform each action that could benefit her child.

This argument is unsound because Premise 2 ' is false. I will argue that it trades on an ambiguity in the notion of a defeasible duty. However, first I will address an alternative argument against Premise 2'. It might be thought that Premise 2' is false because it ignores the importance of probability in defeasible duties to benefit: it obviously does not follow from the fact that one has a duty to benefit someone that one has a duty to do anything that has any probability however small of benefitting them. ${ }^{47}$ But, as explained earlier, the view on which there is a defeasible duty to perform any action that could benefit your child does take probability into account in determining whether you actually have a

\footnotetext{
${ }^{47}$ I thank Jeff McMahan for pressing me on this.
} 
duty to perform a given action. The strength of the defeasible duty - and thus the strength of the countervailing reasons required to defeat the duty - will depend on the expected value of the action, which is determined by the size of the benefit and the probability of benefitting. Nonetheless, one may well want to argue that very small chances of benefitting should not give rise to even defeasible duties to benefit: that I have a defeasible duty to benefit someone does not mean I am liable to be called upon to justify failure to take very small chances of benefitting him or her. I think this is correct. Nonetheless, it is worth giving the further argument about the ambiguity in the notion of the defeasible duty to benefit. First, this argument has interesting implications for our understanding of duties to benefit. Second, I will use it in showing that a retreat to the claim that a mother has defeasible duties to perform each act that will benefit their child will not resolve the problem.

As Thomas E. Hill notes:

In saying "You have a duty to ...," we may intend either to state a general principle or to declare that the person is required to do something on a particular occasion. Consider, for example, "It is your duty (here and now) to help that man" and "It is your duty to help others (sometimes)."48

\footnotetext{
48 Thomas E. Hill, Dignity and Practical Reason in Kant's Moral Theory. (Ithaca: Cornell U. P., 1992), p. 158. Hill discusses this ambiguity in the context of defending Kant's claim that imperfect duties admit of exceptions on the grounds of inclination against W.D. Ross's objection that we cannot have a duty that we are free to do or not as we feel inclined. W.D. Ross, Kant's Ethical Theory (Oxford, Oxford University Press, 1954).
} 
The claim that a mother has a defeasible duty to benefit her child is what Hill calls a general principle. Hill argues that some general principles allow us an important type of latitude, they allow us the freedom whether or not to perform an action on a given occasion, even though we recognise that it is the type of action that falls under the principle, so long as we are ready to perform sufficient acts of that type on other occasions. ${ }^{49}$ Consider the general principle that I have a defeasible duty to benefit others. As the examples of supererogation discussed in the previous section show, there are many occasions when I can recognise that an action (e.g. running in a charity race) would benefit others and thus falls under this principle, but I do not have a defeasible duty to perform that action.

Hill's view is not universally accepted. Many will be unconvinced that there are general principles which allow us this kind of latitude. ${ }^{50}$ Nonetheless, his observations raise an important question about the scope of claims that a person has a defeasible duty to perform some general type of behaviour, $\mathrm{B}$. What do such claims imply about our defeasible duties on the particular

\footnotetext{
${ }^{49}$ Hill, Dignity and Practical Reason, p. 155.

50 Jeff McMahan suggested that there might be a merely epistemic rationale for the fact that some duties appear to allow us a certain amount of latitude. The suggestion is that with greater knowledge about the costs and benefits, the frequency with which the situations in which the duty applies might arise and so on, we could know the conditions of defeasibility in particular cases and that therefore there would not be the sort of personal discretion Hill describes. I am doubtful this would work. First, there seem to be cases in which all of these are known and yet there is no defeasible duty to benefit, for example the case described above in which you could help your sister learn her lines for the school play. Second, suppose we know that situations in which you could help others at a moderate sacrifice to yourself are likely to arise very frequently. Should we assume that you have a defeasible duty to help in each case, but that this is more easily defeated because of the high expected frequency? It seems to me at least as plausible that the high expected frequency means you do not have defeasible duty to help in each case.
} 
occasions when we have an opportunity to perform some action, $\varphi$, which is an instance of B-ing? I suggest that when B is a general type of behaviour, we distinguish between maximal and non-maximal defeasible duties to B:

An agent has a maximal defeasible duty to B if and only if, she has a defeasible duty to B to the greatest extent possible. Thus for any action, $\varphi$, if $\varphi$ is an instance of B-ing, then she has a defeasible duty to $\varphi$ or to perform some alternative action which involves Bing to the same or greater extent. ${ }^{51}$

An agent has a non-maximal defeasible duty to B if and only if, she has a defeasible duty to B but does not have a defeasible duty to B to the greatest possible extent .

Non-maximal duties are defined negatively. I leave open what forms a non-maximal duty might take. The most obvious suggestion perhaps is that it could take the form of a sufficiency duty, requiring agents to B to a significant enough extent. However, most non-maximal duties do not seem to take this very simple form. For example, the duty to benefit others doesn't seem to simply require us to do enough to benefit others - it can require us to perform particular actions.

\footnotetext{
${ }^{51}$ My notions of maximal and non-maximal duties are partly inspired by one of the distinctions Hill picks out between perfect and imperfect duties. Hill, Dignity and Practical Reason in Kant's Moral Theory, p. 155-165.
} 
The difference between maximal and non-maximal defeasible duties is not a question of strength. Maximal defeasible duties are still defeasible and can be defeated by sufficient countervailing considerations. Very weak maximal duties that are easily defeated by countervailing considerations are theoretically possible. The key difference between maximal and non-maximal defeasible duties is a difference in the scope of liability to be called upon to justify one's actions. If an agent has a maximal defeasible duty to $\mathrm{B}$, then she must be able to provide sufficient countervailing considerations to justify each missed opportunity to B. Each potential instance of B-ing falls within the scope of the defeasible duty and therefore failure to B in that instance requires justification. In contrast, if an agent has a non-maximal duty to $\mathrm{B}$, then she need not be able to provide sufficiently weighty countervailing considerations to justify each missed opportunity to B. Justification is not required for each potential instance of Bing. When it comes to duties to benefit, this means that if an agent has a maximal defeasible duty to benefit a person then she must be able to provide sufficient countervailing considerations to justify failure to take each action that would benefit the person (or to take some alternative action that would benefit the person as much or more); if she has a non-maximal duty to benefit, then she is not required to provide such countervailing considerations to justify each failure to benefit. Part of understanding a non-maximal duty to benefit involves unpacking exactly when the agent is required to provide such justification to avoid blame.

A non-maximal duty to benefit does not generate a defeasible duty to perform each potentially beneficial action. This means that, if some duties to benefit are non-maximal, we should reject Premise 2' (If one has defeasible duty 
to benefit a person, and a given action would benefit that person, one has a defeasible duty to perform that action.) If some duties to benefit are nonmaximal, the argument described above is unsound. Some may argue that there are no non-maximal defeasible duties. The cases of supererogation discussed above suggest that the defeasible duty to benefit others is non-maximal. But I will not focus here on defending that claim here. This is because there is something close to Premise 2' that is true:

Premise 2": If one has a maximal defeasible duty to benefit a person, and a given action could benefit that person, one has a defeasible duty to perform that action or to perform some alternative action that benefits them to the same extent or more.

Premise 2" can function as a premise in the following argument:

Premise 1": A mother has a maximal defeasible duty to benefit her child.

Premise 2": If one has a maximal defeasible duty to benefit a person, and a given action would benefit that person, one has a defeasible duty to perform that action or to perform some alternative action that benefits them to the same extent or more.

Conclusion: Therefore a mother has a defeasible duty to perform each action that would benefit her child or to perform some alternative action that benefits them to the same extent or more. 
It is thus crucial to establish whether a mother has a maximal defeasible duty to benefit her child. If a mother has a maximal defeasible duty to benefit her child, then the revised argument can be used to establish that a mother has a defeasible duty to perform each action that would benefit her child or to perform some alternative action that benefits them to the same extent or more. If a mother cannot have a maximal defeasible duty to benefit her child, then this shows either that she does not have a defeasible duty to benefit her child or that some defeasible duties to benefit are non-maximal. I will now argue that a mother cannot have a maximal duty to benefit her child. Such a duty would have unacceptable implications for the mother's self-ownership and wellbeing.

As noted above, Rosamund Scott has argued against the view that the special relationship between a pregnant woman and her foetus in a voluntary pregnancy gives rise to a duty to make virtually unlimited sacrifices for the sake of the foetus. Scott's oppponent's view trades on the thought that in voluntary pregnancy the woman would have been able to avoid being subject to such an onerous duty. If she is not prepared to make extreme sacrifices, she can abort or decline to conceive. Scott argues that this suggestion "ignore[s] the place of pregnancy within our (indeed any) society", failing to recognise "the acute personal importance to the woman (and partner) of reproduction".52

Scott's argument highlights two reasons to limit the duties associated with pregnancy and motherhood. The first is society's interest in reproduction. As Scott puts it: “... if society wants to continue to exist, then some people - women

\footnotetext{
52 Scott, Rights, Duties and the Body, p. 99
} 
in fact - have to bear children." 53 The second is the woman and her partner's interest in reproducing. Having children is a fundamental part of a good life for many people.54 Given the importance of pregnancy to both the state and to individuals' happiness, it is important that women are able to choose to become or remain pregnant without taking on intolerable moral burdens. Interestingly, these very same considerations may seem to speak in favour of stringent maternal duties. Both the state and individuals have strong reasons to want to ensure that pregnancies and children's upbringing are managed well so that the outcomes are good. Partly for this reason, I agree that pregnant women and mothers (and fathers) do have significant duties to their offspring. Nonetheless, the moral burdens associated with pregnancy and parenthood must not be intolerable. Even if society has an interest in the people who become parents being as good as they can be, it has a much stronger interest in enough people becoming parents to keep society going. Given that society depends upon significant numbers of people making this choice, this should be a choice that people can make without being subject to intolerable moral burdens. Moreover, if being a parent is a fundamental part of a good life for many people, then people have a strong interest in being able to access that good without taking on intolerable moral burdens. Otherwise, people face the choice of either missing

\footnotetext{
53 Scott, Rights, Duties and the Body, p. 97

54 This is not meant to imply that many people believe that anyone who does not have children has not had a good life. Very roughly, my picture is that there are various different forms of good life for humans. A key form of the good life for humans has parenting as a fundamental part. I leave it open whether there is a single good life for each person and the extent to which what counts as a good life for a given person depends upon their own choices. Nonetheless, for many people, even if a good life would still be possible without children, this would require radical readjustment that would have significant costs.
} 
out on an incredibly important good or "voluntarily" taking on duties which undermine their wellbeing.

Scott also notes the political component of decisions about what burdens a mother can be fairly asked to accept. ${ }^{55}$ There are two facts that make minimising the moral burdens of pregnancy desirable on ground of gender equality. First, most people who are able to become pregnant are women. ${ }^{56}$ Thus if there are high costs associated with being pregnant, these will fall disproportionately on women. Second, a woman might become pregnant unexpectedly and feel that abortion is not an option for her. Sterilisation and celibacy, the only ways to be sure of avoiding unplanned pregnancies, both bring considerable costs.

Scott's argument can be extended to show that pregnant woman and mothers in general cannot be under a maximal defeasible duty to benefit their child, where this is seen as implying that a mother who fails to perform a potentially beneficial act is liable to moral criticism unless she can produce sufficient countervailing considerations. A maximising defeasible duty to benefit would place an intolerable burden on mothers.

Opportunities to affect the wellbeing of one's child are pervasive. This is most extreme during pregnancy. As Cunningham J. observes in a US Court Case, "As opposed to the third-party defendant, it is the mother's every waking and sleeping moment which, for better or worse, shapes the prenatal environment which forms the world for the developing fetus." ${ }^{57}$ Post birth, there is more

\footnotetext{
${ }^{55}$ Scott, Rights, Duties and the Body, p. 97

${ }^{56}$ Some transsexual men and some non-gendered persons are also able to become pregnant.

57 Stallman v. Younquist, 531 NE 2d 355 (Ill 1988). See Scott, Rights, Duties and the Body, p. 98-9. See Kukla, Mass Hysteria, p. 129-130 for discussion of the regulation of pregnant women's lives.
} 
separation between mother and child. ${ }^{58}$ Nonetheless, the mother still faces almost constant opportunities to benefit or harm her child. Indeed, if and when breastfeeding, the mother still faces the concern that anything she puts into her own body may also be ingested indirectly by the baby. Breastfeeding mothers are often advised to avoid common medications, some foods, and even certain emotions. Mothers are strongly encouraged to breastfeed, meaning that there is pressure for a 'good mother' to prolong the state in which what the mother ingests and what the baby ingests are linked. There is pressure to continue the intertwinedness of mother and baby in other ways as well: mothers face significant pressure to fulfil the role of sole primary care-provider, ideally giving up work for at least a significant amount of time to devote themselves to the baby. ${ }^{59}$

In addition, there is a high level of uncertainty about the risks and benefits to one's child of many everyday activities. Concern over the ethical issues concerning research involving pregnant women mean that there is often little

\footnotetext{
58 Some of what I say about post-partum mothers also applies to fathers too. I do not focus on fathers here because paternal behaviour is not generally - and certainly has not been historically -under the same scrutiny as maternal behaviour. Of course, it might be argued that paternal behaviour should be subjected to the same scrutiny as maternal behaviour is now. Someone might hold that both fathers and mothers have maximal defeasible duties to benefit their children and that therefore we should drastically alter our views about fathers. This position is vastly preferable to that implicit in much discussion of maternal behaviour, which assumes that mothers - and only mothers - have maximal defeasible duties to benefit. Nonetheless, for the reasons discussed in the text, I believe that neither mothers nor fathers should have maximal defeasible duties to benefit. I thank Jeff McMahan for pressing me on this.

${ }^{59}$ C.F Amy Mullin, Reconceiving Pregnancy and Childcare: Ethics, Experience, and Reproductive Labour (New York: Cambridge University Press, 2005), p. 7-9, 122-153; Kukla, Mass Hysteria, p. $177-80$
} 
experimental evidence available. ${ }^{60}$ Even when evidence is available, judgment about how to weigh up risks and benefits is needed. There is a sea of conflicting advice about the risks and benefits of many everyday activities during pregnancy from eating peanut butter to swimming. Post-natally, there is controversy about everyday aspects of childcare from how long it is safe to have a small child in a car seat to whether using plug socket covers increases or decreases the risk of electrocution.

This combination of pervasiveness and uncertainty means that a defeasible duty to perform each action that might benefit one's child would be intolerably burdensome. Such a duty would require constant self-surveillance on the mother's part: she would have to be prepared to defend and justify every decision she makes. Moreover, she would have to do so against a background of uncertainty, where little is understood about which activities really are significantly risky and about how to weigh up potential risk. Even assessing whether an activity poses a potential benefit may require considerable research. The mental and emotional energy required to perform this task is huge. In the current social context, this is exacerbated by a significant pressure to 'play it safe', overestimating potential risk or benefit to the child and underestimating cost to the mother.

Given this, being held to a maximal defeasible duty to benefit would have unacceptable implications for women's self-ownership and wellbeing. If held to such a duty, the mother's every action over an extended period of time would (a)

\footnotetext{
${ }^{60}$ See Kukla, "Equipoise, Uncertainty, and Inductive Risk in Research Involving Pregnant Women" for argument that our understanding of the risks of research concerning pregnant women is often flawed, failing to recognize the risks of not undertaking such research manifested both by untreated health conditions and by 'off-label' treatment.
} 
be supposed to be directed towards the wellbeing of another and (b) be open to public scrutiny. I have argued elsewhere that such a situation, in which one's body is reduced to an instrument of another's wellbeing, is incompatible with self-ownership. ${ }^{61}$ Such failure to respect a person's self-ownership is bad in itself. Moreover, it seems likely to have significant adverse effects on the woman's wellbeing: when mothers inevitably fail to live up to such extreme demands they suffer unwarranted guilt and shame ${ }^{62}$; the very process of trying to meet such standards is physically and mentally exhausting; finally women who are engaged in a constant battle to meet this duty miss out on opportunities to do other things that may benefit them in, for example, their careers or other interests. Duties of this kind are unacceptable even if based on voluntarily assumed special relationships - particularly if, as in the maternal case, there is strong reason to limit the moral burdens associated with a special relationship. ${ }^{63}$ My primary focus here is the question of what defeasible duties individual mothers have rather than the question of what it would be reasonable for a social policy to demand from mothers. My claim is that if a mother is held to a maximal defeasible duty to benefit her child, this imposes an intolerable moral burden, failing to respect her self-ownership and undermining her well-being. On my view, endorsing a maximal defeasible duty to benefit one's child involves

\footnotetext{
61Fiona Woollard, Doing and Allowing Harm, (Oxford: Oxford University Press, 2015).

62 See footnotes 26,27 and 28 for details of sociological studies emphasising guilt and shame felt by new mothers in the context of infant feeding. This seems to be a particularly striking example of a more general phenomenon.

63 This line of argument implies that the kinds of duties we have may depend upon contingent facts such as the history of gender inequality. I do not think this is problematic, particularly for duties that are generated by roles or relationships that may have quite different morally relevant features in different circumstances.
} 
holding that it is legitimate to hold mothers to such a maximal defeasible duty and thus that it is legitimate to impose this intolerable moral burden on them. I claim that we should not recognise this as legitimate. My argument is not undermined by the suggestion that in a society with high levels of parental neglect, it might be best to recognize maximal defeasible duties in the expectation that mothers who are generally conscientious would not face demands for justification whenever they failed to provide some minor benefit because those concerned with benefits to children would achieve more good by targeting others. On my understanding, this amounts to the claim that we should say there is a maximal defeasible duty to benefit while hoping that good mothers will not be held to this duty. In our current social context, such hope would seem to me to misplaced. This is not to ignore that the advice to pregnant women and mothers is intended to be addressed not only to conscientious mothers but also to women who might be induced by this advice not to harm their children in various serious ways. I suggest that social policy must balance these important needs - and indeed the very real benefits proper information can enable mothers to provide for their babies - with the burdens placed on mothers. Holding that mothers have maximal defeasible duties to benefit their children wrongly discounts the burdens on mothers by suggesting that the mother is liable to public scrutiny and moral censure. I suggest that a full, correct account of maternal duties would allow public scrutiny and censure to be appropriately targeted, protecting vulnerable children without placing undue burdens on mothers. ${ }^{64}$

\footnotetext{
${ }^{64}$ I thank Jeff McMahan for pressing me on this.
} 
I have argued that there cannot be a maximal defeasible duty to benefit one's child where this is understood as involving a defeasible duty to perform every action that might benefit the child. Could we then retreat to the claim that mothers have a defeasible duty to perform each action that would benefit the child or is expected to benefit the child? I do not think that this would either justify current practices of discussing maternal behaviour nor provide a plausible account of maternal duties. First, I take it that one of the important things that my discussion above does is to show further argument is needed to determine the implications of a defeasible duty to benefit a person or group of persons. This argument applies equally well to the restricted claim. We cannot move, without argument, from the existence of a defeasible duty to benefit one's child to a defeasible duty to perform particular actions that would benefit one's child. Second, given the uncertainty about the risks and benefits to one's child, it is not clear what a defeasible duty to perform each action that will benefit one's child would mean. If it means that you are liable to justify failure to perform actions that there is reason to think would benefit your child then the worries about pervasiveness and uncertainty still apply and the duty is intolerably burdensome. If it only means that you are liable to justify failure to benefit when benefit is certain, then (a) this does not justify current practices; (b) this does not provide an adequate account of maternal duties because it does not explain what a mother's duties are in cases of uncertainty and, as most cases involve uncertainty, therefore leaves the majority of cases unsettled.

I have argued against a maximal defeasible duty for a mother to benefit her child on the grounds that the associated burdens would undermine her selfownership and threaten her wellbeing. Nonetheless there may be cases where 
parents are morally required to make considerable sacrifices for their children. Consider:

Kidney: Fred's son has a rare kidney disorder and requires a kidney to survive. Of those tested, Fred is the only match.

Some people would think that Fred is morally required to donate his kidney to save his son. He may be required to do so even if donating the kidney will leave him in pain for the rest of his life. If a parent's relationship to his or her child can require such huge sacrifices, does this undermine my argument that a maximal defeasible duty to benefit one's child is ruled out by the burdens associated with such a duty?65

There are significant disanalogies between the burdens associated with a duty to donate an organ in cases like Kidney and those associated with a maximal duty to benefit one's child. First, the costs associated with donating in cases like kidney may fall on either parent. The reasons discussed above to limit the burdens associated with pregnancy on grounds of gender equality do not apply. But even ignoring such considerations, the cases are disanalogous. The kidney case involves a rare and unexpected need for sacrifice to prevent a serious harm. Pregnancy and new motherhood are not rare or unexpected experiences. Many women expect to spend substantial amounts of time during their most productive years either pregnant or as new mothers. Pregnancy and motherhood should be seen as part of "the normal course of events". I have argued elsewhere that the extent to which a requirement to aid another

${ }^{65}$ I thank Jeff McMahan for this objection. 
undermines self-ownership depends on both the severity of the demand (how much are you required to sacrifice when the duty applies) and its expected frequency (how likely is it that you will be required to make such a sacrifice). For a person's body to genuinely belong to them, they must have an authority over that body which puts it, for the most part, at their own use rather than at the use of others. This authority need not be absolute: an agent's body can still belong to her even if she is sometimes required to use it for the good of others. Nonetheless, it must be a genuine authority and not merely a theoretical one. If the requirements to aid are too severe or too frequent, then the agent does not have strong enough authority over her own body and lacks genuine selfownership. Recognising the importance of expected frequency allows us to explain common intuitions about requirements to aid: most people think we are required to make much more significant sacrifices if we find a child drowning in a pond than in cases such as receiving an appeal from UNICEF to save a drowning child. I argue that this is because Pond cases have a low expected frequency and thus a requirement to make large sacrifices in such cases is compatible with the agent's body being, for the most part, at her own use. ${ }^{66}$ In contrast, a duty to make large sacrifices in UNICEF cases would both be severe and have a high expected frequency. Similarly, a duty to donate one's kidney in the kidney cases provides less of a threat to self-ownership than a maximal duty to benefit one's child, because the maximal duty to benefit one's child is both very costly (as argued above) and has a high expected frequency. Of course, it is open to someone to argue that a duty to donate one's kidney even in rare cases

\footnotetext{
${ }^{66}$ See Woollard, Doing and Allowing Harm (Oxford University Press, Oxford, 2015),
} Chapters 7 and 8. 
would be so severe that it would undermine self-ownership - which may underlie the fact that in law parents cannot be required to donate blood, let alone a kidney. If this is correct, I see it as supporting the claim that parents cannot have duties to donate their kidneys in such cases, rather than as reason to hold that becoming a parent requires you to give up self-ownership. ${ }^{67}$

I thus suggest that a mother cannot have a maximal defeasible duty to benefit her child. We should reject the revised version of the argument from the defeasible duty to benefit one's child.

\section{A DEFEASIBLE DUTY TO AVOID RISK OF HARM}

Traditional deontological morality draws a distinction between strong negative duties to avoid harming and weaker positive duties to benefit, holding that while we are generally not required to benefit others, we are required to refrain from harming them, even at considerable cost to ourselves. ${ }^{68}$ We might think that a mother has a maximal defeasible duty to reduce the risk of harm to her child. The moral censure involved in discussion of maternal behaviour might then be understood as related to potential violations of this duty, rather than a duty to benefit. 69

\footnotetext{
${ }^{67}$ I thank Jeff McMahan for pressing me on this.

${ }^{68}$ Katherine A. Knopoff stresses the importance of this distinction (("Can a Pregnant Woman Morally Refuse Fetal Surgery", California Law Review 79 (1991), p. 518) but acknowledges that the unique character of pregnancy poses problems in applying the distinction (Ibid, p. 520). ${ }^{69}$ One way to respond to these claim is to appeal to the interests of the child i.e. stress is bad for the child, it is bad for the child to bring it up in a culture of over-protectiveness where the aim is to eradicate risk. I thank Elselijn Kingma for suggesting this. Although I think such arguments may provide reason to take some risks / refrain from picking up some benefits, I resist them for two reasons: (1) they can add another thing for pregnant women to feel guilty
} 
One issue here is that not enough attention has been played to the application of the distinctions in question. For example, Ian Kennedy describes a pregnant woman who fails to accept medical care or follow a specific diet as "pos[ing] a threat to the safety of others" or as "exposing the fetus to harm". ${ }^{70}$ This suggests that he sees it as a violation of a negative duty to avoid harming. Yet we would not normally see failure to take such steps to prevent someone coming to harm as violation of the negative duty not to harm others. Instead, it would typically be classed as failure to benefit.

There are two different distinctions here. First there is the distinction between suffering a harm and failing to enjoy a benefit. When I am not picked to receive a free sample of ice cream, I miss out on a benefit but I do not suffer harm. Second, there is the distinction between bringing about and failing to prevent. If I don't pull my friend out of the path of a car which hits him and breaks several of his bones, he suffers a harm, but I do not harm him - I simply fail to prevent harm to him. The claim that a mother has a duty to avoid harm to her child seems to shift in meaning between the claim that a mother has a duty not to bring about harm to her child and the much stronger claim that a mother has a duty not to either bring about or to fail to prevent harm. During arguments for the existence of such a duty, it often seems as if only the weaker, negative duty, is included. During exposition of what the duty involves, the stronger reading is often assumed - or worse still any action that leads to a less than optimum outcome for the child is seen as bringing about harm. Thus it does not

\footnotetext{
about or be required to justify; (2) they may give the impression that the value of the woman's freedom/ happiness is derivative on what is best for the child.

70 Ian Kennedy, "A woman and her unborn child: rights and responsibilities" in Peter Byrne

(ed) Ethics and Law in Healthcare and Research (Chichester: John Wiley and Sons, 1990), p. 172-3.
} 
seem as if the duty to avoid harm, as applied in the literature, can be defended by appeal to a distinction between negative and positive duties.

We also need to pay attention to the difference between a duty to avoid bringing about harm and a duty to avoid all risk of doing harm. Our negative duties to avoid harming others do extend to duties to avoid some risks of harm. Nonetheless, it doesn't seem as if they come into effect whenever there is any risk at all of harm. Some risks are thought to be so insignificant that they don't even give rise to a defeasible duty not to take such risks of bringing about harm. In discussion of maternal behaviour, it seems to be assumed that mothers have a defeasible duty to avoid even very small risks of harm. Again, the discussion of maternal behaviour assumes a duty to avoid risk of harm that cannot be defended by an appeal to strict negative duties to avoid harming others.

It might be thought that we could clean up the arguments here, accepting a maximal defeasible duty to reduce the risk of doing harm but simply being very careful that we only apply this when the mother is genuinely doing rather than merely allowing harm and the risk is appropriately significant. I have some concerns about this approach, particularly in the case of pregnant women. A maximal defeasible duty for a pregnant woman to reduce risk of doing harm would be very different from the standard duty not to harm others. First, the interdependence between mother and foetus means that such a duty would involve a much greater imposition that the standard duty to avoid harming. Classic deontological morality assumes that the duty not to harm is usually relatively easy to fulfil: we assume that normally we can go along, living our 
normal lives, without even having to think about the duty not to do harm. ${ }^{71}$ In contrast, every aspect of the mother's ordinary behaviour has the potential to harm the foetus. Second, the distinction between bringing about and failing to prevent harm may not apply to maternal behaviour in a straightforward way. ${ }^{72}$ Whether an agent counts as doing or merely allowing harm may depend upon whether the objects on which she acts belong to her, to the victim of harm or to a third party. According to my analysis, I count as merely allowing harm if I only substantially affect what belongs to me or what is (relative to the victim) unowned; I count as doing harm if I substantially affect what belongs to the victim or what some third party intended to be used to protect the victim from harm. ${ }^{73}$ Many others, for example Jeff McMahan, Kai Draper, Timothy Hall, Matthew Hanser also give accounts of the doing/allowing distinction which make reference to ownership..$^{74}$ These analyses of doing and allowing depend on

\footnotetext{
${ }^{71}$ This assumption may be outdated, as in the modern world we may frequently breach negative duties not to harm others through supporting exploitation by participation in global trade or through contributions to global warming.

${ }^{72}$ C.F. Fiona Woollard and Elselijn Kingma, “Can I Harm My Foetus? Pregnancy, physical indistinctness, and difficult deontological distinctions." (work in progress); Katherine A. Knopoff, "Can a Pregnant Woman Morally Refuse Fetal Surgery", p. 520, Kukla, Mass Hysteria, p. 211-212, Scott, Rights, Duties and the Body, pp. 82-83, for discussion of the difficulty of applying the positive/negative distinction to pregnancy.

${ }^{73}$ See Fiona Woollard, Doing and Allowing Harm (Oxford: Oxford University Press 2015). 74 Jeff McMahan, “Killing, Letting Die, and Withdrawing Aid." Ethics 103 (1993): 250-79. Kai Draper, "Rights and the Doctrine of Doing and Allowing." Philosophy and Public Affairs 33 (2005): 253-80. Timothy Hall, “Doing Harm, Allowing Harm and Denying Resources." Journal of Moral Philosophy 5 (2008): 50-76. Matthew Hanser, “Killing, Letting Die and
} Preventing People from Being Saved." Utilitas 11 (1999): 277-95. Note ownership of resources plays a role in Hall and Hanser's theories because they each argue that withdrawals of resources fall into a third moral category which cannot be classified alongside standard doings or standard allowings, ownership is relevant for actions within this third category. 
clear boundaries between agent and victim. When the potential victim is growing inside the agent, and may even count as part of the agent's body ${ }^{75}$, we do not have the appropriate boundaries.

We face similar problems in applying the distinction between suffering a harm and failing to receive a benefit. When the foetus' wellbeing is so bound up with the mother's actions, when its very existence depends upon her, it is very difficult to determine whether a given state counts as a harm or a benefit. One way to understand harm/ benefit is by comparing how well off the subject is in some respect relative to an appropriate baseline: the subject has been harmed if and only if they are made worse off than the baseline and benefitted if they are made better off than the baseline. Selecting the appropriate baseline is always tricky, but even more so in the case of the foetus and the mother. Because there is no default level of foetal wellbeing that is independent of the mother's behaviour, it is very unclear what should be used as a baseline. An alternative is to hold that a state is a harm if and only if it involves non-comparative badness e.g. pain. This approach throws up problems given that bringing a frail human being into existence inevitably leads to them suffering some intrinsically bad states. It also seems to miss some of the things that we want to count as harms.

Overall, the nature of the relationship between mother and child needs to be taken into account when working out how the duty not to do harm applies to maternal behaviour. We cannot read the mother's duties to the child straight off from the duties of one separate independent adult to another. In particular, we cannot reach conclusions about whether or not a mother has a maximal

\footnotetext{
${ }^{75}$ See Elselijn Kingma "Were you a part of your mother? The Metaphysics of Pregnancy", Mind, forthcoming.
} 
defeasible duty not to do harm or to prevent serious risks of harm to her child until we understand how the doing/allowing distinction and the harm/ benefit distinction apply in pregnancy and early motherhood. That is a significant project which is beyond the scope of this paper.

\section{CONCLUSION}

I have suggested that much of the discussion of maternal behaviour puts unjustified pressure on mothers in part because it mistakenly assumes that a mother has a defeasible duty to perform any action that may benefit her child. I have argued that she does not have such a duty. Nonetheless, I do not deny that a mother has some very strong defeasible duties to her child.

My (rough) suggestion for an alternative understanding of the moral demands of motherhood is as follows. Mothers have a duty to love and care for their child, to consider the child's wellbeing and a defeasible duty to give their child a good life and protect them from unreasonable overall risk of harm. This leads to a strong but non-maximal defeasible duty to benefit. This duty does not translate to a defeasible duty to $\varphi$, for each individual act or pattern of behaviour, $\varphi$, that would benefit the child or reduce risk of harm to the child. Some individual acts or patterns of behaviour will carry an uncontroversial and obviously significant risk of harm or potential for benefit. If this is so, the mother may have a defeasible duty either to avoid the act (if it contains some significant risk of harm) or to perform it (if it contains an obviously significant potential for benefit). When a mother does not have a defeasible duty to perform a given action that may produce benefit or reduce risk of harm, the potential benefit or harm is normally instead a moral reason for the mother to behave in a certain 
way. Such moral reasons differ from defeasible duties in that the mother who does not comply with them is not liable to moral criticism if she is unable to produce sufficient countervailing reasons. 